\title{
Germinação de urediniósporos de Phakopsora pachyrhizi em diferentes métodos de armazenamento
}

\author{
Elisandra Batista Zambenedetti ${ }^{1,2}$, Eduardo Alves², Edson Ampélio Pozza², Dejânia Vieira de Araújo ${ }^{2}$
}

\author{
${ }^{1}$ Bolsista do CNPq.; ${ }^{2}$ Departamento de Fitopatologia, Universidade Federal de Lavras, Cx. Postal 3037, CEP 37200-000, Lavras, MG, e-mail: \\ ealves@ufla.br. \\ Autor para correspondência : Eduardo Alves \\ Data de chegada: 23/05/2005. Aceito para publicação em: 22/05/2006.
}

\section{RESUMO}

Zambenedetti, E. B.; Alves, E, Pozza, E.A .; Araújo, D.V. Germinação de urediniósporos de Phakopsora pachyrhizi em diferentes métodos de armazenamento. Summa Phytopathologica, v.33, n.1, p.83-85, 2007.

O objetivo deste trabalho foi avaliar o efeito de diferentes métodos de armazenamento na viabilidade de urediniósporos de P. pachyrhizi. Para isso foram armazenadas folhas herborizadas com urediniossoros $\left(24^{\circ} \mathrm{C}\right)$; urediniósporos em dessecador $\left(10^{\circ} \mathrm{C}\right)+$ nitrogênio líquido $(-$ $196^{\circ} \mathrm{C}$ ) após 60 dias, geladeira $\left(4^{\circ} \mathrm{C}\right)$, deep-freezer $\left(\right.$ de -60 a $\left.-80^{\circ} \mathrm{C}\right) \mathrm{e}$ nitrogênio líquido. A cada trinta dias avaliou-se à porcentagem de germinação em meio ágar-água $2 \%$ à temperatura de $25^{\circ} \mathrm{C}$. Urediniósporos armazenados em nitrogênio líquido apresentaram maior porcentagem de germinação ao final das avaliações (270 dias). Urediniósporos armazenados em dessecador apresentaram $0 \%$ de germinação aos 60 dias e quando transferidos para o nitrogênio líquido voltaram a apresentar até $30 \%$ germinação. Urediniósporos armazenados nas demais condições apresentaram grande redução na germinação no primeiro mês e com 90 dias esta chegou a zero. Concluiu-se que o melhor método de armazenamento para urediniósporos de $P$. pachyrhizi foi o nitrogênio líquido.

Palavras-chaves: ferrugem da soja, preservação de inóculo, nitrogênio líquido.

\begin{abstract}
Zambenedetti, E. B.; Alves, E, Pozza, E.A.; Araújo, D.V. Germination of urediniospores from Phakopsora pachyrhizi on different techniques of preservation. Summa Phytopathologica, v.33, n.1, p.83-85, 2007.

The objective of this study was to evaluate the effect of different storage methods on the viability of the urediniospores of $P$. pachyrhizi. Urediniospores were collected and stored in five different conditions: detached dry leaves $\left(24^{\circ} \mathrm{C}\right)$, desiccator $\left(10^{\circ} \mathrm{C}\right)+$ liquid nitrogen $(-$ $196^{\circ} \mathrm{C}$ ) after 60 days, refrigerator $\left(4^{\circ} \mathrm{C}\right.$ ), deep-freezer (from $-60^{\circ} \mathrm{C}$ to $\left.80^{\circ} \mathrm{C}\right)$ and liquid nitrogen $\left(-196^{\circ} \mathrm{C}\right)$. The percentage of germination from stored urediniospores was evaluated every thirty days in wateragar medium. Urediniospores stored in liquid nitrogen presented the

highest germination percentage after 270 days of storage. In desiccator, the germination was zero at ninety days of evaluation, and when urediniospores were transferred to and kept in liquid nitrogen, the germination was up to $30 \%$. The urediniospores stored under others conditions presented a decline in germination at sixty days and at the ninety days the germination declined to zero. Based on these results, the most efficient way of storing urediniospores of $P$. pachyrhizi was using liquid nitrogen.
\end{abstract}

Additional keywords: liquid nitrogen, rust soybean, inoculum storage.

A manutenção do inóculo de fungos da ordem Uredinales é realizada, preferencialmente, no próprio hospedeiro vivo. Entretanto, essa técnica apresenta vários inconvenientes, entre eles o de ser laboriosa, necessitando da manutenção das plantas hospedeiras com o patógeno o ano inteiro, o que é difícil em algumas regiões, além de se correr o risco de contaminações com outros isolados ou raças e até mutações do patógeno devido às várias inoculações $(7,8)$.

Vários métodos de armazenamento visando preservar os urediniósporos de Uromyces phaseoli var. phaseoli e Puccinia triticina em curto prazo fora do hospedeiro já foram avaliados, como o uso de dessecador (9) e congelador (1), respectivamente. Para armazenamento em longo prazo tem sido utilizado o nitrogênio líquido, como pode ser observado no trabalho de Ryan \& Ellison (8) que testaram técnicas de criopreservação para Puccinia spegazzinii. Porém, pouco se sabe a respeito do armazenamento de urediniósporos de Phakopsora pachyrhizi Sydow \& P.Sydow. Diante do exposto o objetivo deste trabalho foi estudar o melhor método de armazenamento de urediniósporos de P. pachyrhizi.

O trabalho foi conduzido no Departamento de Fitopatologia da Universidade Federal de Lavras com inóculo de P. pachyrhizi, proveniente da EMBRAPA-SOJA, Londrina-PR, multiplicado na cultivar de soja BRS 154. Os esporos foram coletados com leves 
batidas nas folhas com urediniossoros, sobre papel branco e acondicionados em microtubos. Parte da amostra foi submetida à teste de germinação inicial, utilizando metodologia descrita abaixo. Os demais urediniósporos foram acondicionados em microtubos e foram submetidos ao armazenamento no escuro em: i-Geladeira a $4^{\circ} \mathrm{C}$, ii-Deep-freezer com temperatura entre $60^{\circ} \mathrm{C}$ e $-70^{\circ} \mathrm{C}$, iii-Nitrogênio líquido a $-196^{\circ} \mathrm{C}$, iv-Nitrogênio líquido após 60 dias em dessecador, com zero porcento de germinação e v-Folha herborizada em temperatura de $24^{\circ} \mathrm{C}$. Para o teste de germinação dos urediniósporos utilizaram-se suspensões de $1 \mathrm{mg}$ de urediniósporos de $P$. pachyrhizi/mL de água destilada $+25 \mu \mathrm{L}$ de tween 20 . A suspensão foi padronizada em câmara de Neubawer para $3 \times 10^{4}$ urediniósporos $/ \mathrm{mL}$ de água, colocada em Becker com água e uma gota de tween 20 e
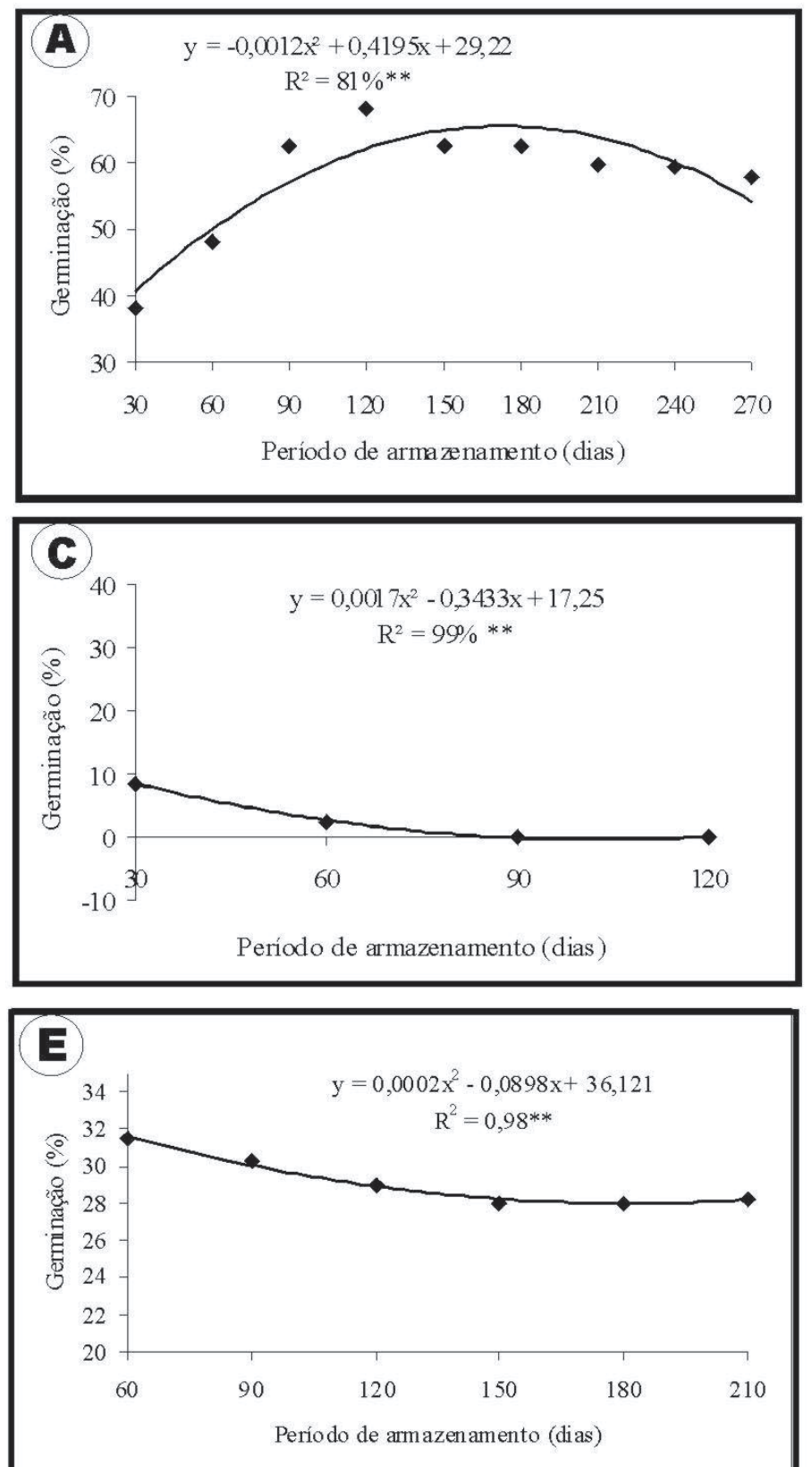

Figura 1. Porcentagem de germinação, ao longo do tempo, para urediniósporos de Phakopsora pachyrhizi armazenados em nitrogênio líquido (A), folha herborizada (B), geladeira (C), deep-freezer (D), dessecador e, após 60 dias, transferidos para nitrogênio líquido (E).
Tabela 1. Área abaixo da curva de progresso da germinação (AACPG) de urediniósporos de Phakopsora pachyrhizi.

\begin{tabular}{cc}
\hline TRATAMENTOS & AACPG \\
\hline Nitrogênio líquido & $4928,3 \mathbf{a}^{*}$ \\
Dessecador-nitrogênio líquido & $2115,7 \mathbf{b}$ \\
Deep-freezer & $989,5 \mathbf{c}$ \\
Folha herborizada & $181,7 \mathbf{d}$ \\
Geladeira & $169,2 \mathbf{d}$ \\
\hline CV $(\%)$ & 3,83 \\
\hline
\end{tabular}

* Médias com mesma letra, não diferem entre si, pelo teste de Tukey a $5 \%$ de probabilidade.

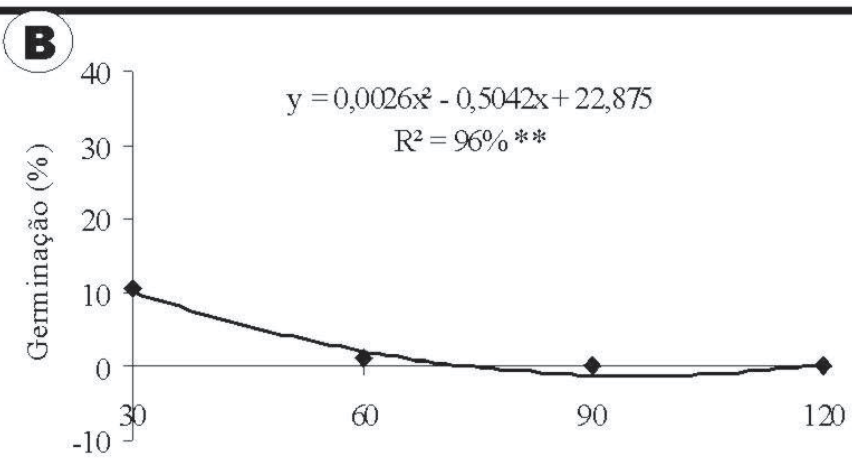

Período de armazenamento (dias)

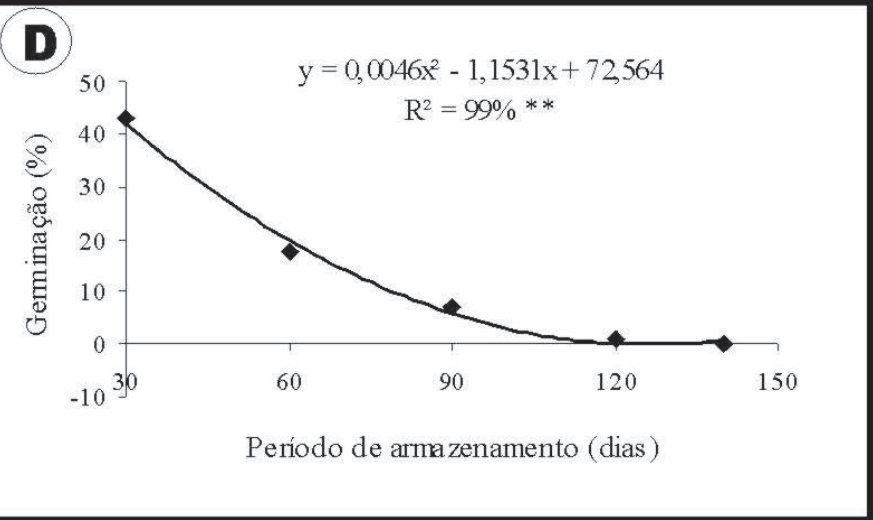

agitada. Em seguida, adicionou-se $50 \mu \mathrm{L}$ da suspensão, em cada placa de Petri, com nove $\mathrm{cm}$ de diâmetro, contendo meio ágarágua $2 \%$, a qual foi espalhada com alça de Drigalski. As placas foram acondicionadas em $\mathrm{BOD}$ a $25^{\circ} \mathrm{C}$, no escuro, por 4 horas. Após a incubação, avaliou-se a germinação em microscópio de luz. A cada 30 dias repetiu-se o mesmo processo para o preparo de novos testes de germinação até 270 dias após o armazenamento.

O delineamento experimental foi inteiramente casualisado, com cinco tratamentos e quatro repetições, sendo cada repetição constituída por uma placa de Petri dividida em quatro compartimentos, onde observaram-se 50 urediniósporos, totalizando 200 por placa. Os dados foram integrados usando-se a área abaixo da curva de progresso da germinação (AACPG) ao longo do período do experimento, adaptada de Campbell \& Madden (2). Os dados do somatório da germinação foram elevados ao quadrado, devido a grande quantidade de valores zero. Depois de detectada a ausência da normalidade de variância dos erros, os dados 
foram transformados para $\sqrt{ } \mathrm{x}+0,5$. A variável significativa no teste F foi comparada por meio do teste de médias de Tukey a $5 \%$ de probabilidade, para comparar os métodos de germinação, enquanto ao longo do tempo foram ajustados modelos de regressão. As análises foram feitas no programa SISVAR (3).

A porcentagem de germinação antes do armazenamento variou entre 87 e $90 \%$, sendo observada queda, trinta dias após o armazenamento em todos os tratamentos (Figura1). Houve diferença significativa entre os métodos de conservação para AACPG. A maior AACPG foi obtida em nitrogênio líquido seguido do método do dessecador-nitrogênio líquido, cujos urediniósporos foram transferidos para o nitrogênio líquido após 60 dias, e deep-freezer. Os métodos de conservação em folha herborizada e geladeira apresentaram menor AACPG (Tabela 1). Furtado et al. (4) estudando a preservação de $P$. pachyrhizi também verificaram manutenção da germinação de urediniósporos em deep-freezer por um período mais longo do que a geladeira e freezer, porém estes autores avaliaram o processo até 138 dias. No presente trabalho, a germinação de urediniósporos foi testada até 270 dias, fato que possibilitou um conhecimento mais amplo a respeito da manutenção do inóculo do patógeno.

Nos urediniósporos armazenados em nitrogênio líquido, observou-se $40 \%$ de germinação após 30 dias, apresentando aumento progressivo até os 120 dias, chegando a $70 \%$, estabilizando-se, próximo desse valor, até 270 dias (Figura 1A). A queda na germinação aos 30 dias após o armazenamento e posterior aumento, provavelmente foi devido à quebra de dormência devido a baixas temperaturas depois de serem liberados dos urediniossoros. Os urediniósporos armazenados no dessecador chegaram a zero porcento de germinação aos 60 dias, porém aos trinta e 60 dias depois de transferidos para o nitrogênio líquido, apresentaram $20 \%$ e $30 \%$ de germinação, respectivamente, com queda de menos de $10 \%$ até o final das avaliações (Figura 1E). Portanto, alguns urediniósporos armazenados no dessecador não perderam a viabilidade, sendo evidenciado a ocorrência de dormência, a qual foi parcialmente quebrada em nitrogênio líquido. Esses dois casos são contrários ao encontrado por Loreing et al. (5) com o fungo P. graminis var. tritici, quando a temperatura ultra-fria do nitrogênio líquido induziu dormência dos urediniósporos a qual foi revertida por calor. Estes fatos indicam que quando os urediniósporos de $P$. pachyrhizi são dispersos por correntes aéreas em elevada altitude, nas quais as temperaturas são extremamente baixas, a viabilidade pode ser mantida por um período de tempo maior, além da possibilidade de ocorrer a quebra da dormência. Portanto, a capacidade de disseminação destes urediniósporos a longas distâncias pode estar no fato de as baixas temperaturas manterem sua viabilidade, já que os mesmos a perdem com pouco tempo longe do urediniossoro. Este fato já foi verificado para a ferrugem do trigo $P$. graminis var. tritici nos Estados Unidos, onde ocorre disseminação de esporos dos campos do Sul para o Norte do País (6).

Os urediniósporos armazenados em folhas herborizadas apresentaram germinação de $2 \%$ e $0 \%$ aos 60 e 90 dias, respectivamente (Figura 1B). Os urediniósporos armazenados em geladeira também tiveram zero porcento de germinação aos 90 dias (Figura 1C). No armazenamento em deep-freezer, os urediniósporos perderam o poder germinativo aos poucos, sendo que aos 30 dias após o armazenamento, a germinação estava entre $50 \%$ e $55 \%$, chegando a zero aos 150 dias após a avaliação (Figura 1D).

Sendo assim, verificou-se que as temperaturas mais baixas mantiveram o poder germinativo dos urediniósporos por mais tempo, fato também verificado por Ryan \& Ellison (8). O nitrogênio líquido foi o melhor método de armazenamento para urediniósporos de $P$. pachyrhizi, pois, além de manter o inóculo viável por longo período, também permitiu a quebra de dormência. Novos estudos estão sendo realizados para verificar a infectividade em plantas, dos urediniósporos armazenados em nitrogênio líquido.

\section{REFERÊNCIAS BIBLIOGRÁFICAS}

1. Akai, S. On the resistance of urediospores of Puccinia triticinia to low temperature. Annals of the Phytopathology Society of Japan, Tokyo, v. 19, n.1-2, p.15-17, 1954.

2. Campbell, C.L.; Madden, L.V. Introduction to plant disease epidemiology, New York: J. Wiley, 1990. 532p.

3. Ferreira, D.F. Análise estatística por meio do SISVAR para Windows versão 4.0. In: Reunião Anual da Região Brasileira da Sociedade Internacional de Biometria, 45, 2000, São Carlos. Programa e Resumos. São Carlos: UFScar, 2000. p.235.

4. Furtado, G. Q.; Alves, S. A. M.; Czermainski, A. B. C.; Massola Jr., N. S. Preservação dos urediniósporos de Phakopsora pachyrhizi. Summa phytopathologica, Botucatu, v.31, supl., p.79, 2005 (Resumo).

5. Loering, W. Q.; Harmon, D.L. Effect of thawing temperature on urediospores of Puccinia graminis var. tritici frozen in liquid nitrogen. Plant Disease, St. Paul, v. 46, n. 3, p. 299-302, 1962.

6. Nagarajan, S.; Singh, H. Long-distance dispersion of rust pathogens. Annual Review of Phytopathology, Palo Alto, v.28, n.1, p.139-153, 1990 .

7. Prescott, J. M.; Kernkamp, M. F. Genetic stability of Puccinia graminis var. tritici in cryogenic storage. Plant Disease, St. Paul, v. 55, n. 2, p. 695-696, 1971.

8. Ryan, M. J.; Ellison, C. A. Development of a cryopreservation protocol for the microcyclic rust-fungus Puccinia spegazzinii. CryoLetters, London, v.24, n.1, p.43-48, 2003.

9. Shein, R.D.; Rotem, J. Temperature and humidity effects on uredospore viability. Mycologia, St. Paul, v.57, n.3, p.397-403, 1965 